\title{
OCORRÊNCIA, FREQUÊNCIA E DANOS DAS PRECIPITAÇÕES DE GRANIZO NA REGIÃO METROPOLITANA DE CURITIBA
}

\author{
Nathan Felipe da Silva Caldana \\ Universidade Tecnológica Federal do Paraná, Londrina, PR, Brasil. \\ nathancaldana@gmail.com \\ Paulo Henrique Caramori \\ Instituto Agronômico do Paraná, Londrina, PR, Brasil. \\ pcaramori@gmail.com \\ Angela Beatriz Ferreira da Costa \\ Sistema Meteorológico do Paraná - SIMEPAR, Curitiba, PR, Brasil. \\ angelabcosta@gmail.com \\ Glauco Marighella Ferreira da Silva \\ Universidade Federal do Paraná, Curitiba, PR, Brasil. \\ glaucomarighella@hotmail.com
}

\begin{abstract}
RESUMO
As condições de tempo e clima são essenciais para a agricultura e o desenvolvimento da sociedade, entretanto, sua dinâmica pouco compreendida pode comprometer algumas atividades humanas. A precipitação de granizo, um evento extremo caracterizado por precipitação de água em estado sólido, tem alta capacidade destrutiva tanto no meio rural quanto no urbano, gerando transtornos e prejuízos frequentes. A Região Metropolitana de Curitiba (RMC) possui um grande contingente populacional com grande vulnerabilidade a eventos extremos meteorológicos, sendo necessários estudos que auxiliem para o planejamento na região. Dessa forma objetivou-se neste trabalho identificar a formação, frequência, ocorrência e os danos de precipitações de granizo na RMC. Para isso, utilizou-se dados disponibilizados pelo Instituto Agronômico do Paraná (IAPAR), Sistema Meteorológico do Paraná (SIMEPAR), Defesa Civil do Paraná, jornais publicados e cartas sinóticas disponibilizas pelo Instituto Nacional de Pesquisas Espaciais (INPE). O recorte temporal utilizado foi de 1986 a 2017. Identificou-se que o eixo de Campo Largo a São José dos Pinhais é o mais vulnerável e com maior frequência de granizo, chegando a registrar 4 precipitações de granizo por ano. A estação de primavera e o mês de setembro registraram maior número de eventos e sua principal formação foi por meio dos sistemas convectivos.
\end{abstract}

Palavras-chave: vulnerabilidade, risco climático, eventos extremos.

\section{OCCURRENCE, FREQUENCY AND DAMAGES OF GRANIZO PRECIPITATIONS IN THE METROPOLITAN REGION OF CURITIBA}

\begin{abstract}
Weather and climate conditions are essential for agriculture and the development of society; however, their little understood dynamics can compromise some human activities. Hail precipitation, an extreme event characterized by solid state water precipitation, has a high destructive capacity both in rural and urban environments, generating frequent disturbances and damages. The Metropolitan Region of Curitiba (RMC) has a large population with great vulnerability to extreme meteorological events, and studies are needed to assist planning in the region. The objective of this work was to identify the formation, frequency, occurrence and damages of hail precipitation in the RMC. For this purpose, data from the Agronomic Institute of Paraná (IAPAR), the Meteorological System of Paraná (SIMEPAR), the Civil Defense of Paraná, published newspapers and synoptic charts made available by the National Institute of Space Research (INPE) were used. The temporal cut used was from 1986 to 2017. It was identified that the Campo Largo to São José dos Pinhais axis is the most vulnerable and with the highest frequency of hail, reaching 4 hail precipitations per year. The spring season and the month of September registered a
\end{abstract}


greater number of events and their main formation was through the convective systems.

Keywords: vulnerability, climatic risk, extreme events.

\section{INTRODUÇÃO}

A precipitação de granizo pode ser um fenômeno extremamente danoso para as práticas desenvolvidas pela sociedade e para a dinâmica da natureza. Porém, como destacado por Martins et al. (2017), por ser um evento pontual e de curto prazo sua detecção por estações meteorológicas é pouco representativa. No estado do Paraná o Instituto Agronômico do Paraná (IAPAR) possui uma rede de estações agrometeorológicas com registros históricos de ocorrências desse fenômeno.

Diversos trabalhos em todo o mundo demonstram como são grandes os impactos da precipitação de granizo em culturas agrícolas, casas, carros, edifícios e na biodiversidade (KREUZ et al., 2002; AMARANTE et al. 2009; VIANA et al., 2009; SILVA et al., 2012; MEZHER, 2012; DOLATI et al., 2014; PUNGE e KUNZ, 2016; MARTINS et al., 2017; PUNGE et al., 2017; CAPOZZI et al., 2018; TREFALT et al., 2018). O tamanho, a intensidade e a duração da precipitação de granizo diferem a severidade dos impactos. Os espaços são atingidos pelos fenômenos naturais de maneira homogênea, porém a vulnerabilidade socioambiental expõe a população a riscos distintos (ALCANTTARA-AYALA, 2002).

"A condição de pobreza de uma determinada população está estreitamente vinculada à condição de formação de riscos e de vulnerabilidade socioambiental" (MENDONÇA, 2005, p. 151). A ocupação de áreas irregulares e de risco associadas às condições socioeconômicas aumenta as consequências dos desastres e os impactos nos grupos sociais. Dessa forma, um fenômeno pode atingir uma região e afetar de maneira diferente a população que ali reside (CIDADE, 2013; FREIRE et al., 2014)

As ocorrências de precipitações de granizo nos estados da região Sul do Brasil não são raras (BEREZUK, 2017). Para o estado do Paraná, Silva et al. (2012) fizeram um levantamento da ocorrência de granizo por jornais e identificaram que esse meio de detecção do fenômeno é noticiado apenas em casos extremos e abrange, em grande parte, eventos ocorridos nas cidades, não dando atenção para o campo. A Região Metropolitana de Curitiba - RMC é a segunda região mais afetada por precipitações de granizo no estado do Paraná (SILVA, et al. 2012). O grande contingente populacional, atrelado ao desenvolvimento econômico desigual contribuem para a vulnerabilidade de riscos de desastres ambientais nesta área (MENDONÇA, 2005).

A agricultura brasileira passa por um processo acelerado de profissionalização e busca por informações que contribuam para o aumento de produção e reduza as perdas e prejuízos. Sendo o clima um fator essencial para a obtenção de boas safras, trabalhos que identifiquem adversidades e auxiliem na tomada de decisão são fundamentais para o planejamento desse setor (CARAMORI et al., 2016; KLANOVICZ, 2013, p. 86).

O granizo é formado em grandes instabilidades atmosféricas, e normalmente, associado a incidências de nuvens do tipo cúmulo-nimbos. A formação ocorre na parte superior da nuvem em que a temperatura é menor e favorece a transformação de gotículas de água em partículas de gelo, com diâmetro médio de 1,5 a $2 \mathrm{~cm}$, que pode variar de 0,5 a $20 \mathrm{~cm}$. Seus principais meios de formação são por sistemas convectivos, instabilidades causadas por passagem de frentes frias ou, em maior escala, pelos Complexos Convectivos de Mesoescala (CCM) (MIDDLETON e MCWATERS, 2002; PUNGE e KUNZ, 2016).

Dessa forma, objetivou-se identificar a formação, frequência, ocorrência e os danos das precipitações de granizo na RMC, fornecendo suporte para o planejamento e tomada de decisões preventivas de combate para o impacto desse fenômeno na região.

Como se trata, normalmente, de um evento local, a medição das ocorrências de granizo é dificultada pela baixa densidade de estações meteorológicas, sendo diversas precipitações ignoradas ou não detectadas pelo observador meteorológico. A utilização de jornais como fonte de 
informação de fenômenos meteorológicos se mostrou satisfatória em diversos trabalhos, principalmente, para adversidades causadas por eventos extremos climáticos como granizo, saraiva, tempestades, geadas e secas (ELY, 2008; SILVA et al., 2012).

\section{MATERIAL E MÉTODOS}

Para a compreensão da espacialização e frequência das ocorrências de granizo na RMC, foram utilizados dados da Defesa Civil do Paraná. A Proteção Civil Brasileira age de acordo com a necessidade da emergência e de serviço a ser prestado por assistência das populações afetadas. A ação é de imediato após o desastre, e as equipes enviadas para o campo são responsáveis por realizar o preenchimento de um relatório descrevendo o fenômeno e os danos resultantes (MARTINS et al., 2017). A Defesa Civil do Paraná é estruturada por oito Coordenadorias Regionais de Defesa Civil, sendo que cada município possui sua Coordenadoria Municipal de Defesa Civil. A obtenção dos dados foi feita por meio do Relatório de Ocorrência de Tempestade local/convectiva Granizo. Os dados coletados foram número de ocorrências, pessoas afetadas e óbitos.

As duas estações agrometeorológicas do IAPAR (Figura 1) localizadas na região possuem tempo de funcionamento diferentes. Para a estação da Lapa foi utilizado o recorte temporal de 1989 a 2017 e para a estação de Pinhais de 1986 a 1998.

Figura 1 - Localização da Região Metropolitana de Curitiba e das estações agrometeorológicas

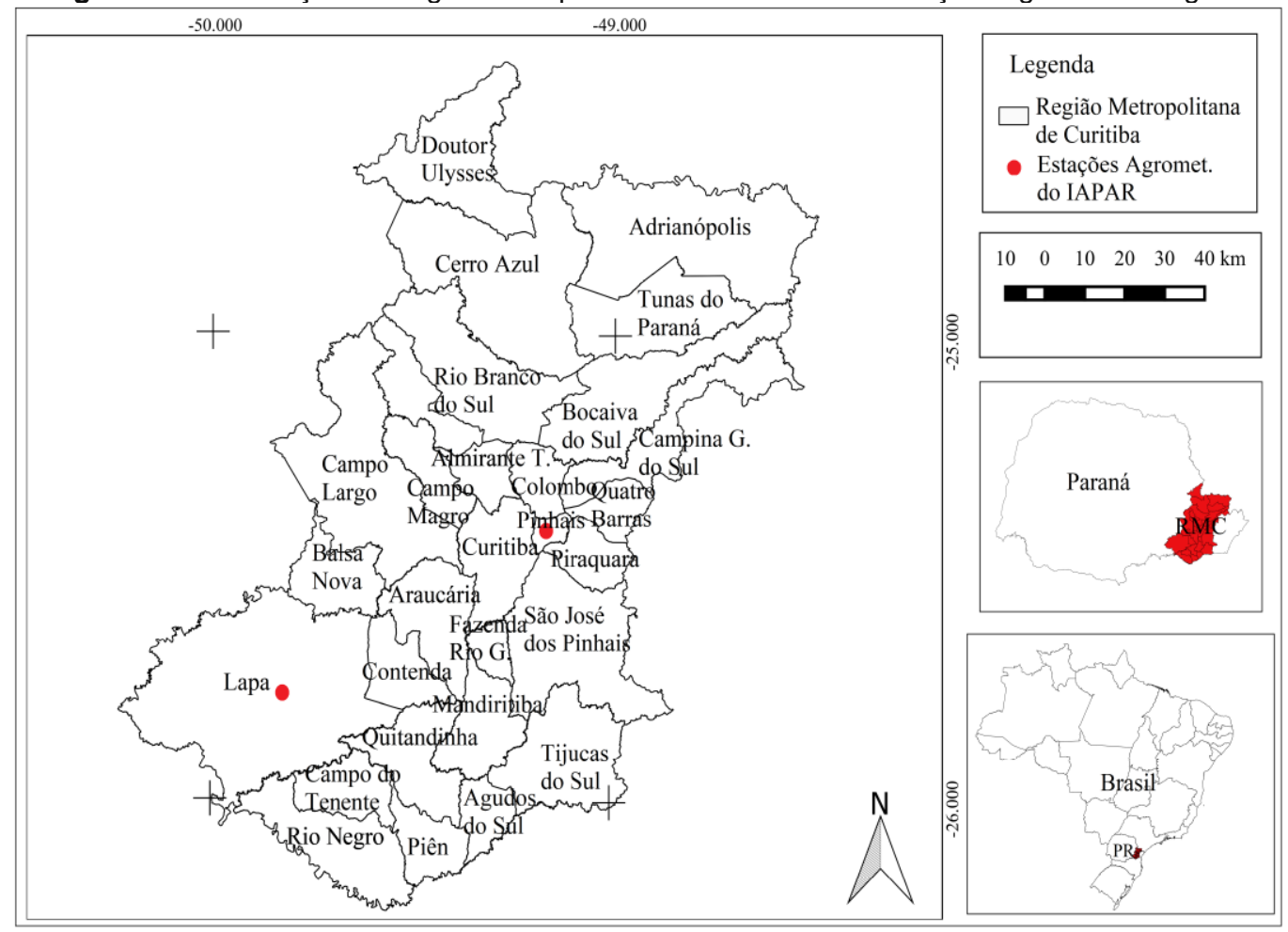

Fonte - IBGE (2018). Organizado pelos autores (2018).

Os dados de granizo fornecidos pelo IAPAR são realizados por relatos de um observador meteorológico, cabendo a este, o discernimento entre granizo e saraiva e a intensidade da precipitação. A intensidade é estabelecida como 3 (Forte), 2 (Médio) e 1 (Fraco).

Para identificar as ocorrências e formação de precipitações de granizo por meio de jornais, Ely (2008) propõe um modelo de planilha para facilitar a catalogação, considerando os seguintes dados: 1) identificação do jornal, data da publicação, título da manchete, título da notícia, localização no jornal; 2) identificação das fontes citadas pela reportagem; 3) tipo de elemento 
climático; 4) tipo de problema causado; 5) localização e escalas (rural e urbano) e 6) observações gerais.

Os jornais são fontes relevantes para aquisição de eventos climatológicos extremos, pois, normalmente, noticiam os impactos de adversidades meteorológicas quando causam danos sociais, econômicos e/ou ambientais, e sendo o granizo responsável por $12 \%$ dos desastres naturais provenientes de fenômenos atmosféricos, é um fenômeno sempre noticiado (MARCELINO et al., 2006). Os principais jornais consultados foram Gazeta do Povo, O Estado do Paraná, Banda B, Tribuna PR, O Bonde e Jornal do Povo Paraná.

Para a análise da formação de granizo, utilizou-se dados publicados e relatório emitidos pelo Sistema Meteorológico do Paraná - Simepar e cartas sinóticas publicadas pelo INPE - Instituto Nacional de Pesquisas Espaciais e CPTEC - Centro de Previsão de Tempo e Estudos Climáticos, considerando a formação de precipitação convectiva, frontal e CCM. O granizo possui solidificação extremamente rápida e ocorre por meio da sublimação, ou seja, passagem do estado gasoso diretamente para o sólido. Normalmente o granizo ocorre como evento localizado, pois consiste em células de precipitação limitadas a abrangência da nuvem cumulunimbus, associada a sistemas convectivos isolados, CCM e frentes frias (MARCELINO et al., 2006; MIDDLETON e MCWATERS, 2002; PUNGE e KUNZ, 2016; TREFALT et al., 2018).

Por meio dessas diferentes bases de dados, foram elaborados mapas temáticos para espacializar as ocorrências e localizar as principais áreas onde ocorrem precipitação de granizo, utilizando o software de geoprocessamento Qgis 2.18. Os gráficos foram tabulados e editados no software Sigmaplot.

\section{RESULTADOS E DISCUSSÃO}

Os dados de ocorrência de granizo noticiado por jornais (Figura 2) foram coletados de 2000 a 2017. Entende-se que para ser noticiado a precipitação de granizo ocorreu de forma extrema e trouxe danos à sociedade.

Figura 2 - Ocorrências de precipitação Granizo noticiados em jornais na Região Metropolitana de Curitiba.

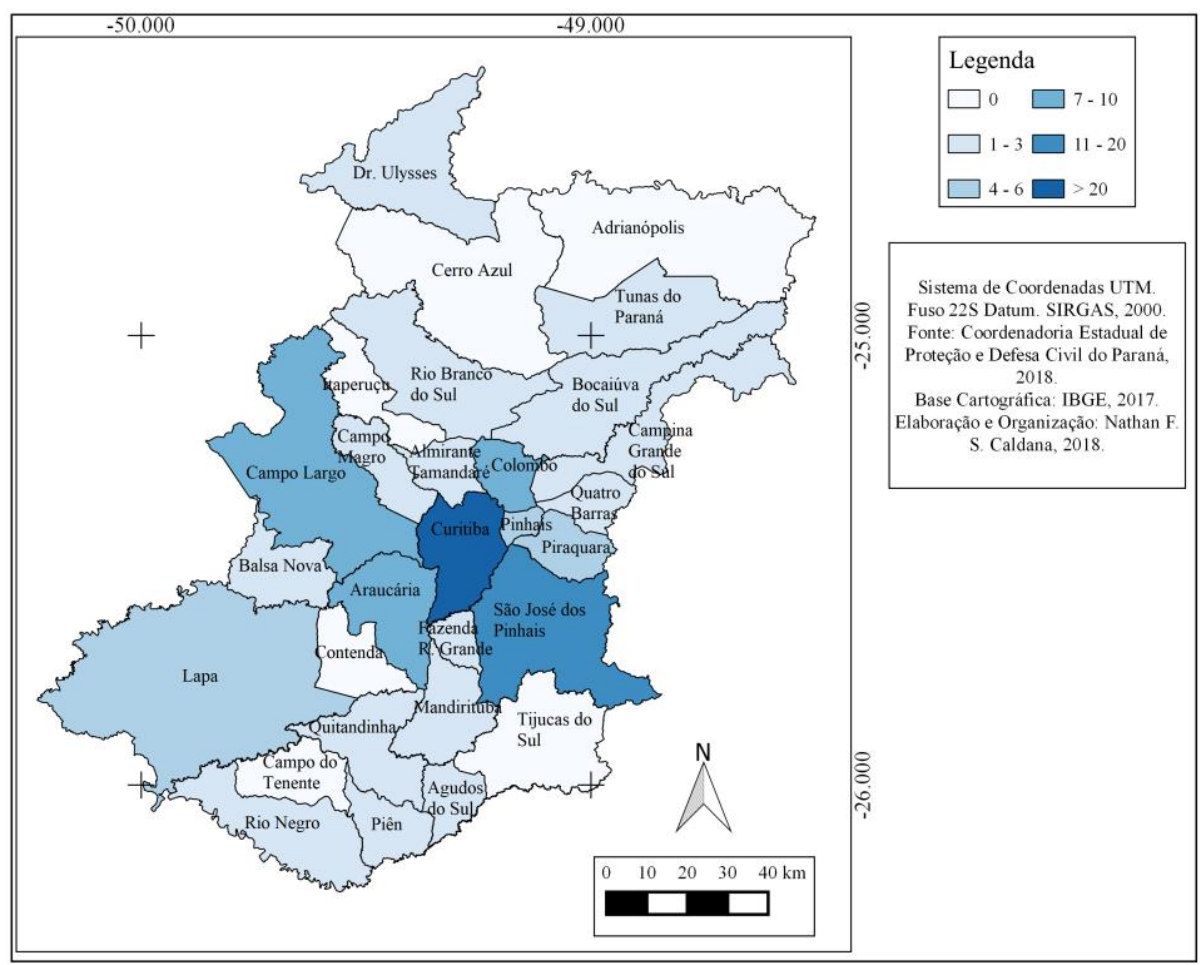

Fonte - Coordenadoria Estadual de Proteção e Defesa Civil do Paraná. Organizado pelos autores (2018). 
Como pode ser observado, o município mais atingido por granizo em registros de jornais foi Curitiba, com 20 ocorrências no período, sendo mais de uma precipitação de granizo por ano. Esse fato pode decorrer que grande parte dos jornais analisados tem sede no município.

Porém, há grande concentração de granizo no eixo entre Campo Largo, Araucária, Curitiba e São José dos Pinhais, todos estes, com mais de dez ocorrências no período, mostrando que pode ser um aspecto regional de maior incidência de precipitação de granizo com danos na RMC.

Regionalmente, os municípios localizados mais ao Sul de Curitiba são mais afetados pelos eventos. Nos municípios sem registro de ocorrência de granizo em jornais não se descarta a ocorrência regionalmente, apenas podem não ter sido noticiados.

Para identificar o número de pessoas afetadas pelas precipitações de granizo (Figura 3) utilizou-se o registro de ocorrência da Coordenadoria Estadual de Proteção e Defesa Civil do Paraná com recorte temporal de 1986 a 2017.

Figura 3 - Número de pessoas afetadas por precipitação Granizo na Região Metropolitana de Curitiba.

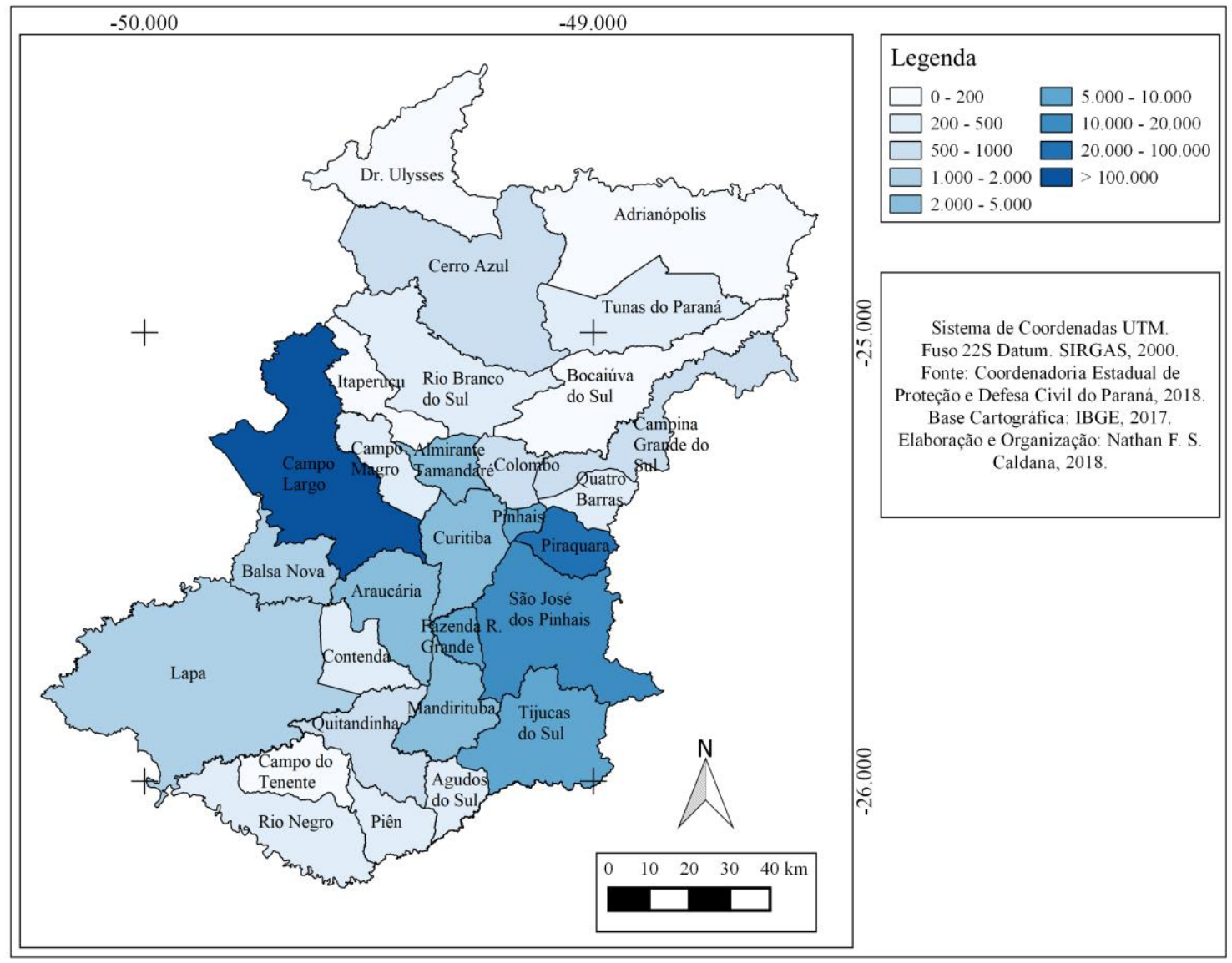

Fonte-Coordenadoria Estadual de Proteção e Defesa Civil do Paraná. Organizado pelos autores (2018).

Diferente do número de ocorrência noticiadas em jornais, os dados de pessoas afetadas da Defesa Civil mostram uma espacialização maior. O município mais afetado foi Campo Largo com 119 mil pessoas afetadas. Em seguida, São José dos Pinhais e Piraquara, com mais de 50 mil pessoas afetadas. Esse fato demonstra a vulnerabilidade socioambiental dos municípios limítrofes a Curitiba, uma vez que, a capital teve pouco mais de 15 mil pessoas afetadas, mesmo sendo mais noticiada e com população maior.

A vulnerabilidade se mostra presente para esse tipo de adversidade meteorológica na região ao constatar que em Campo Largo, em apenas um evento mais de 40 mil pessoas foram afetadas e 
em Tijucas do Sul, também em apenas um evento, 12 mil pessoas sofreram algum tipo de dano, sendo mais de $50 \%$ da população total do município.

Dentre os municípios a norte e a sul de Curitiba na RMC, cabe-se destacar que estes têm em média 10-15 mil habitantes, e mesmo sendo menor o número de pessoas afetadas, se for considerada a população, ganham também expressividade.

Dentre os danos causados por precipitação de granizo noticiados na RMC destacam-se destelhamento e quedas de energia com maior abrangência. Outros danos identificados foram: perdas de produção, carros danificados, desalojados e destruição de casas (figura 4).

Figura 4 - Tipos de danos e número de ocorrências de precipitação Granizo noticiados em jornais e pela

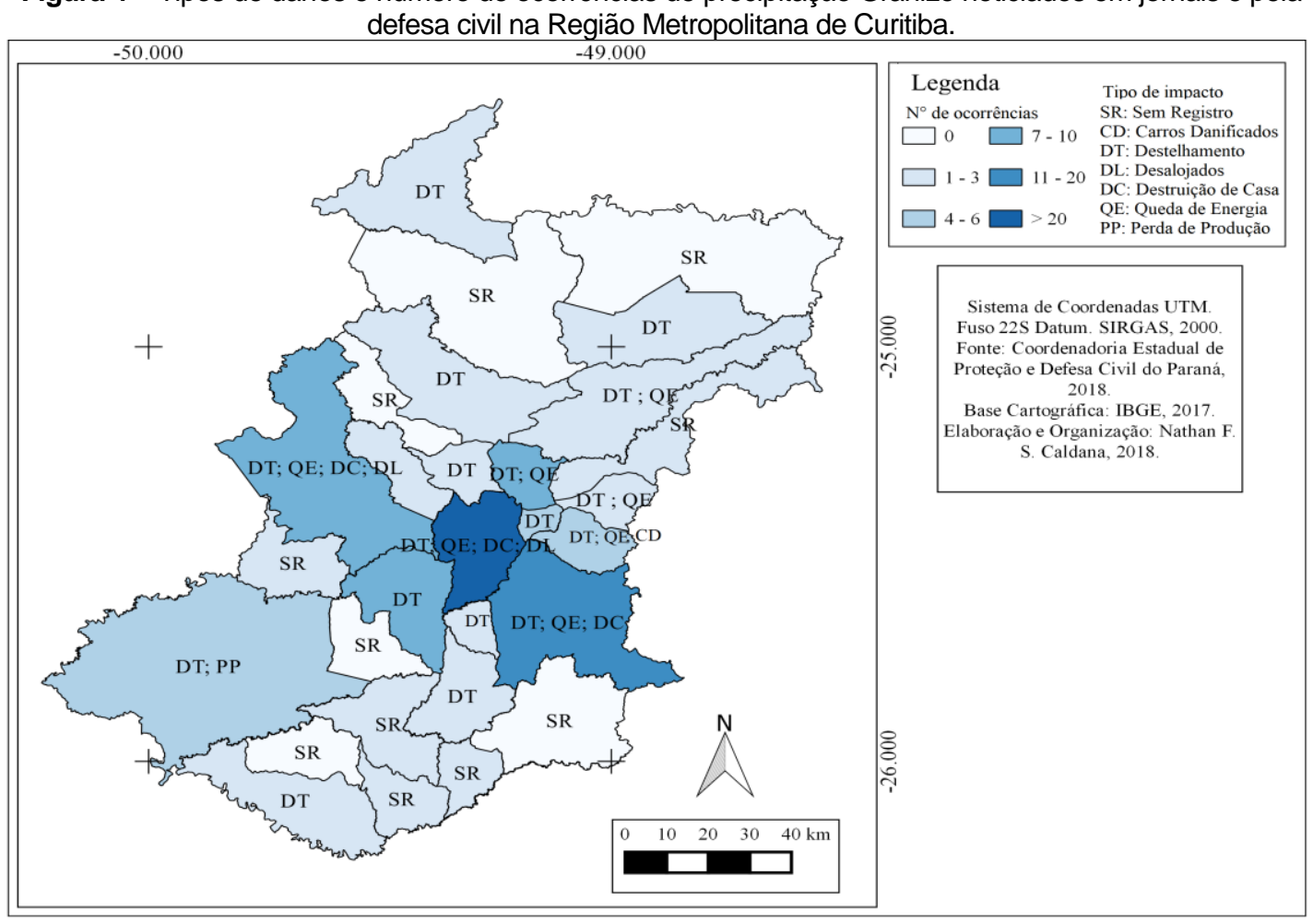

Fonte - Coordenadoria Estadual de Proteção e Defesa Civil do Paraná. Organizado pelos autores (2018).

Como pode ser observado, mais uma vez Curitiba e Campo Largo foram as cidades que registraram mais danos, incluindo destelhamento, queda de energia, destruição de casas e carros danificados. Boa parte dos municípios da região tiveram casos de destelhamentos noticiados, totalizando mais de 40 mil casas destelhadas na região, com maior incidência em São José dos Pinhais, Campo Largo e Curitiba. No caso do destelhamento, sua maior incidência ocorre nas telhas feitas de fibrocimento e barro (CANEVER e LAUREANO JUNIOR, 2016; BEREZUK, 2017; METZ et al., 2017).

$\mathrm{Na}$ Região Metropolitana de Curitiba, assim como em boa parte das metrópoles brasileiras, os riscos no espaço urbano associados aos eventos climáticos, muitas vezes, estão vinculados ao rápido processo de urbanização e a construção civil. Curitiba, principalmente, após a década de 1970, teve sua população aumentada abruptamente e recebeu uma gama de migrantes, em muitos casos, "portadores de baixo preparo técnico-educacional e menos aquinhoados financeiramente", sendo submetidos pelo mercado imobiliário da cidade a uma proliferação de bairros periféricos, muitas vezes, em ocupações irregulares e em habitações com pouco preparo para as adversidades 
climáticas que ocorrem na cidade, como alagamentos, inundações e o granizo. Dessa forma, essa parcela da população passou a conviver com diversos tipos de impactos e riscos ambientais, caracterizados como "vulnerabilidade socioambiental" (MENDONÇA, 2005, p. 143; CIDADE, 2013; MENDONÇA et al., 2016; WILK et al., 2018).

Lapa foi o único município a registrar perda na produção agrícola por adversidades causadas em ocorrência de granizo. O fenômeno afetou principalmente o pequeno produtor, com perda na produção de tomate e batata inglesa. Como a Defesa Civil não presta serviços de reparos para a agricultura, não há estimativa precisa de danos e prejuízos para a região.

Alguns estudos apontam medidas tomadas na região Sul do Estado do Paraná e Oeste e Serrana de Santa Catarina para evitar as perdas na agricultura por adversidades de ocorrências de granizo. A medida mais comum para evitar o impacto direto do granizo nas cultivares é a tela antigranizo. Porém, o seu uso contínuo pode trazer prejuízos no desenvolvimento de algumas espécies por mitigar a radiação direta (CUNHA et al., 2001; KUROSAKI et al., 2007; MOTA et al., 2008; AMARANTE et al., 2009).

Na RMC as únicas estações meteorológicas que registram ocorrência de granizo são Pinhais e Lapa, de acordo com os dados disponibilizados pelo IAPAR. A análise dos dados foi realizada considerando o tempo de funcionamento das estações (Figura 5).

Figura 5 - Ocorrências de granizo nas estações agrometeorológicas do IAPAR

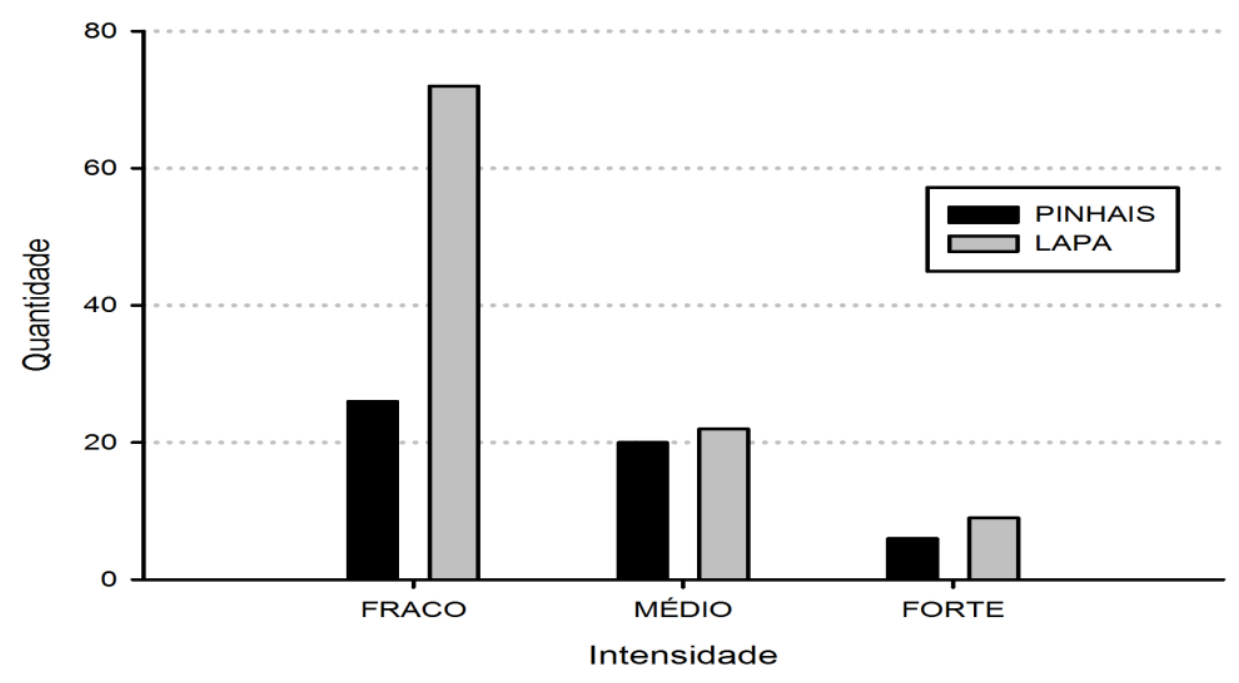

Fonte - IAPAR. Organizado pelos autores (2018)

A estação da Lapa registrou 102 ocorrências em 28 anos de funcionamento, em média 3,6 incidências de granizo por ano. Na estação da Lapa predominaram eventos de fraca intensidade, sendo registrados 21 eventos de média e 9 de forte intensidade.

Já a estação de Pinhais registrou 52 ocorrências em 13 anos, totalizando em média 4 eventos por ano. Nesta estação predominaram-se eventos de fraca intensidade, porém ao comparar com a estação da Lapa, os eventos de médio e forte intensidade ganham destaque, quase se equiparando, com menos da metade de tempo de funcionamento da estação.

Para a identificação da frequência de precipitações de granizo na RMC utilizou-se as escalas temporais mensais e sazonais (figura 6). Os dados analisados são de 2000 a 2017. 
Figura 6 - Ocorrências mensais de granizo nas estações agrometeorológicas do IAPAR

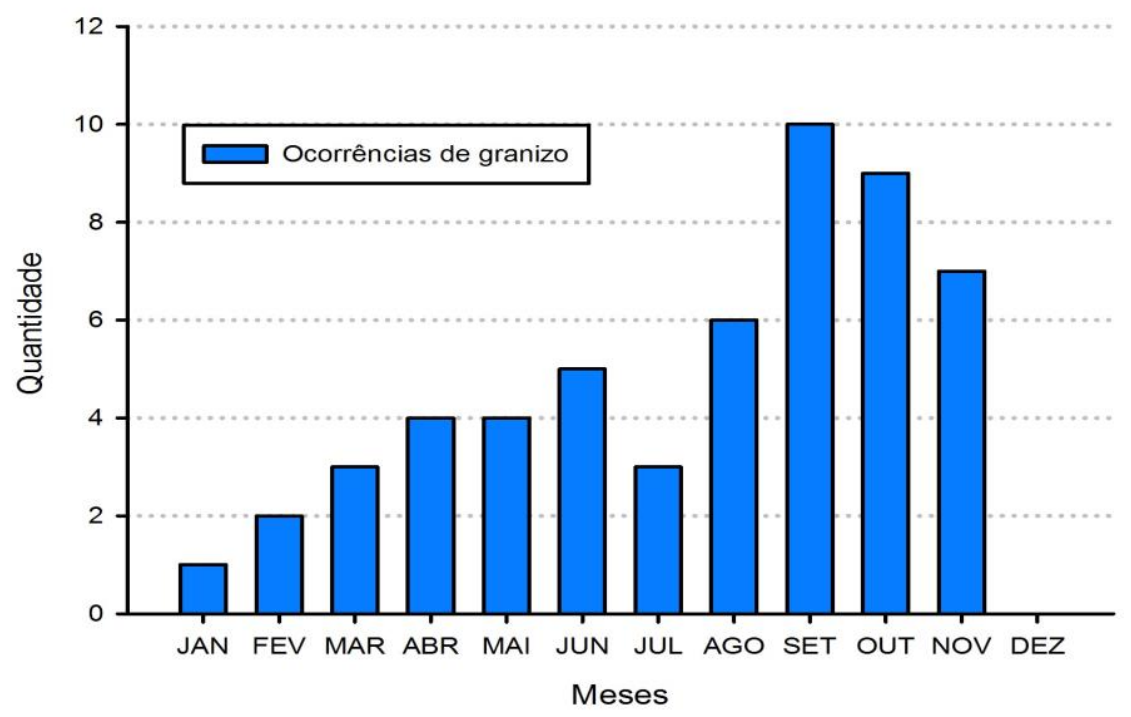

Fonte - IAPAR. Organizado pelos autores (2018)

Sazonalmente, foi possível identificar que a estação do ano com o maior número de ocorrências foi a primavera, com 26 precipitações de granizo. Enquanto no verão os eventos são mais raros, sendo registrados apenas 3 vezes.

Setembro registrou 10 eventos, sendo o mês com maior frequência, enquanto dezembro não teve nenhuma ocorrência. É perceptível que o quadrimestre de agosto a novembro concentrou boa parte das precipitações de granizo na RMC.

Como já mencionado, na região sul do Brasil predominam três tipos de formação de granizo. Os $\mathrm{CCM}$, sistemas convectivos e passagem de frentes frias, gerando instabilidade atmosférica. $\mathrm{Na}$ região sul do brasil, na estação do verão predominam-se as ocorrências dos CCM, definidos como um aglomerado de cumulunimbus cobertos por uma densa camada de cirros. São sistemas de nuvens convectivas, com rápido crescimento vertical e horizontal num intervalo de tempo de 6 a 12 horas, podendo ser identificados por imagens de satélite, devido ao seu formato aproximadamente circular. Dependendo de sua intensidade, pode criar vários núcleos com formação e incidência de granizo. Já para os sistemas convectivos se diferenciam pela menor abrangência espacial, se formando pelo processo de transferência de calor por condução que ocorre em intensos movimentos verticais, levando assim, ao processo rápido de condensação e a formação de Cumulunimbus (SCAGLIONI e SARAIVA, 2004; DAFIS et al., 2017; TREFAULT et al., 2018).

Enquanto nas frentes frias, o encontro da Massa de Ar Polar com a massa de ar quente continental e a umidade gera uma forte instabilidade atmosférica, podendo levar a formação de cumulunimbus e acarretar na formação de granizo (BEREZAUK e SANT'ANNA NETO, 2006; PUNGE e KUNZ, 2016; BEREZUK, 2017).

A identificação dos fenômenos atuantes foi realizada por meio de consultas ao Simepar ou identificação em cartas sinóticas do INPE (Figura 7). 
Ocorrência, frequência e danos das precipitações de granizo na região metropolitana de Curitiba
Nathan Felipe da Silva Caldana

Paulo Henrique Caramori

Angela Beatriz Ferreira da Costa Glauco Marighella Ferreira da Silva

Figura 7 - Tipo de formação meteorológica associada a precipitação de granizo na Região Metropolitana de Curitiba

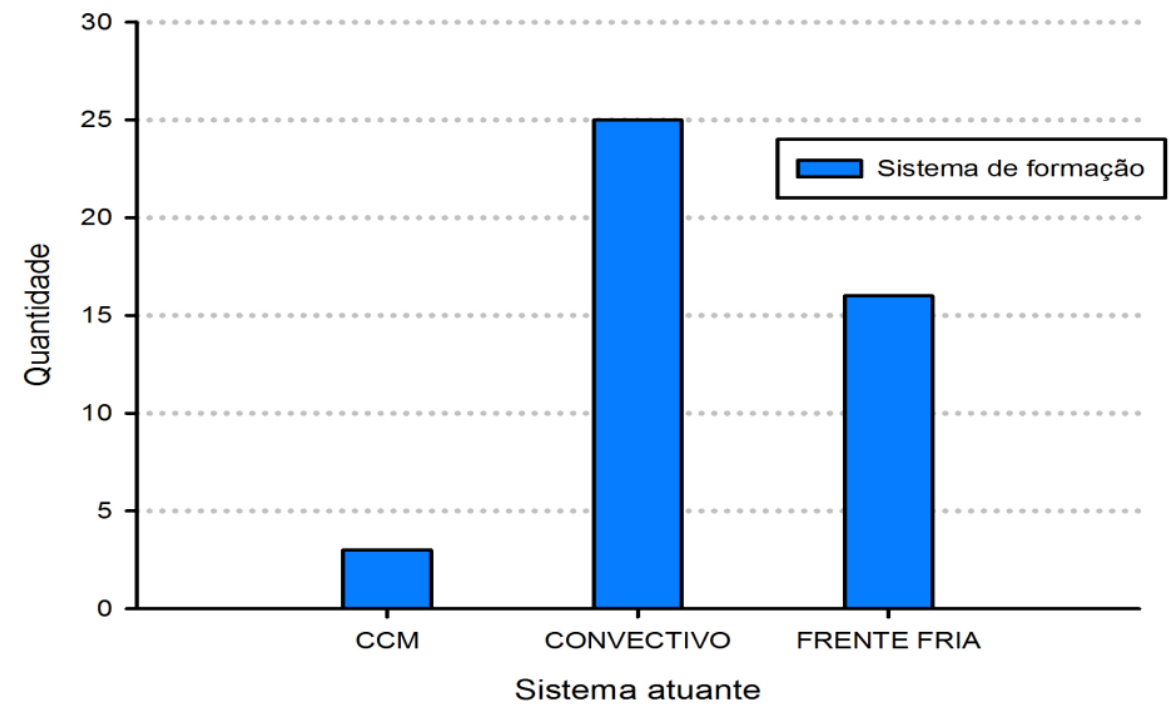

Fonte - SIMEPAR; INPE (2018). Organizado pelos autores (2018)

Pode-se identificar que os sistemas convectivos são os maiores responsáveis por precipitação de granizo na RMC, sendo contabilizados 25 ocorrências, das 53 analisadas. Boa parte de seus registros foram identificados nas estações do outono e primavera.

As precipitações de granizo podem atingir uma área de até $100 \mathrm{~km}$ de extensão, normalmente, relacionados ao CCM, entretanto os eventos mais comuns são entre 8 e $16 \mathrm{~km}$, abrangendo os sistemas convectivos (CUNHA et al., 2001). O fenômeno é mais comum em regiões com relevo acidentado e em regiões continentais de clima quente. No Brasil, as principais áreas afetadas são o Centro-Sul, especialmente nos planaltos de Santa Catarina, Paraná e Rio Grande do Sul (CASTRO, 2003). Os eventos de granizo que ocorrem em grande escala são de maior detecção pelo observador meteorológico e pelos jornais, enquanto os eventos convectivos, em escala menor ou local, são detectados com incidência de danos ou riscos (LYON, 1997; LAURENT et al. 1998; VIANA et al. 2009)

Em seguida aparecem as frentes frias com 16 ocorrências, com maior frequência no outono e inverno. Apenas três foram identificados como CCM, sendo duas ocorrências no verão e uma na primavera. Dez eventos não foram identificados por meio de boletins do Simepar ou identificação nas cartas sinóticas.

A transformação de um evento natural em um desastre natural com implicações para a vida humana surge junto com o sistema humano, quando começamos a interagir e modificar o meio que vivemos e a força da natureza passa a danificar toda a estrutura criada. A situação de desastre natural está intimamente ligada à condição socioeconômica da população e condição de reagir a eventos naturais. Ocorrem no mundo inteiro, mas têm maior repercussão nos países em desenvolvimento, por suas condições econômicas e dificuldade de resposta (ALCÁNTARA-AYALA, 2002; CIDADE, 2013).

Como pode ser identificado, as precipitações de granizo ocorrem com grande frequência na RMC. Dessa forma, cabe à sociedade e ao Estado buscar formas de amenizar os danos e o número de pessoas afetadas por esse evento extremo meteorológico. Como mencionado, a construção civil e os locais de habitações podem estar vinculados ao número de pessoas afetadas e os tipos de danos causados. A exposição de parcela da população regional aos danos causados a este fenômeno pode ser reduzida visando, principalmente, a melhoria no local de habitação e na utilização de materiais resistentes a precipitação de granizo, visto a frequência e a intensidade que ocorrem na região. Locais suscetíveis a frequentes tempestades severas de granizo devem evitar a 
utilização de telhas feitas de fibrocimento e barro, visto não serem resistíveis a esse fenômeno (CANEVER e LAUREANO JUNIOR, 2016; BEREZUK, 2017; METZ et al., 2017).

Para a agricultura não existem valores atuais do efeito de granizo nas lavouras no Paraná, mas estima-se que cerca de $1 \%$ da produção mundial é perdida por efeito do granizo (LYONS, 1997; CUNHA et al., 2001). A proteção no campo pode ser proporcionada por telas antigranizo. As telas têm a função de impedir o impacto físico do granizo com as plantas, evitando o dano causado pelo choque, entretanto existe perda de radiação solar incidente na lavoura. As telas de coloração branca, apesar de durabilidade menor (10 anos) que a da tela preta (15 anos), permitem maior incidência de radiação (KUROSAKI et al., 2007; AMARANTE et al., 2009; BOSCO, et al. 2015; NESET et al., 2018).

Graças à malha urbana da região, não foram estimados grandes danos causados na agricultura. A falta de informação vinculada a esse segmento também se mostrou presente, sendo averiguados apenas nos jornais, uma vez que, a Defesa Civil não presta assistência à agricultura. Porém como observado, diversas técnicas e medidas são tomadas para mitigar o impacto do granizo na agricultura na região Sul do Brasil, porém se torna necessário um levantamento preciso quanto ao número de ocorrência, frequência e tipos de danos causados no campo para buscar medidas plausíveis para cada região.

\section{CONSIDERAÇÕES FINAIS}

Os jornais se mostraram uma fonte satisfatória de detecção de precipitações de granizo na RMC. Como são eventos pontuais e que ocorrem com frequência, as duas estações do IAPAR na região não são suficientes para a detecção dos eventos na escala local. Por meio dos jornais identificou-se maior número de ocorrência em Curitiba, porém, por ser a cidade sede de boa parte destes veículos de informação na RMC, os eventos são mais noticiados na cidade. O eixo Campo Largo, Araucária, Curitiba e São José dos Pinhais foi identificado como a área mais propícia à ocorrência de granizo na RMC. O município de Campo Largo foi o mais atingido na RMC, com mais de 120 mil pessoas afetadas pela ocorrência de granizo.

A estação agrometeorológica da Lapa registrou 3,6 ocorrências de precipitação de granizo por ano, sendo predominantes os eventos de fraca intensidade. A estação de Pinhais registrou 4 ocorrências ao ano e com destaque para eventos de média a forte intensidade, em conformidade com o maior número de danos causados nos municípios limítrofes a Curitiba noticiados por jornais.

A primavera foi a estação com o maior número de ocorrências de granizo, registrando 28 ocorrências em 17 anos. Já o mês de setembro registrou 10 ocorrências, sendo o mês com maior incidência de precipitações de granizo na RMC. A formação nessa estação está principalmente associada aos sistemas convectivos, sendo o principal meio de formação de granizo para a região. As frentes frias contribuem para a formação no inverno, enquanto os CCM para o verão.

Os municípios limítrofes à Curitiba apresentaram maior vulnerabilidade socioambiental ao granizo, sendo necessário planejamento para mitigar os impactos, principalmente nesta área. A vulnerabilidade social é um agravante que precisa ser considerado quando se discute eventos extremos, como o granizo. Apesar dos eventos naturais afetarem os espaços homogeneamente, as pessoas que o habitam não são afetadas nas mesmas proporções.

\section{REFERÊNCIAS}

ALCÁNTARA-AYALA, I. Geomorphology, natural hazards, vulnerability and prevention of natural disasters in developing countries. Geomorphology 47. 2002, pp. 107-124. https://doi.org/10.1016/S0169-555X(02)00083-1

AMARANTE, C. V. T, et al. Disponibilidade de luz em macieiras "fugi" cobertas com telas antigranizo e seus efeitos sobre a fotossíntese, o rendimento e a qualidade dos frutos. Revista Brasileira Fruticultura. Setembro de 2009, p. 664-670. 


\section{https://doi.org/10.1590/S0100-29452009000300007}

BEREZUK, A. G.; SANT'ANNA NETO, J. M. Eventos climáticos extremos no oeste paulista e norte do Paraná, nos anos de 1997, 1998 e 2001. Revista Brasileira de Climatologia, v. 2, 2006.

https://doi.org/10.5380/abclima.v2i0.25370

BEREZUK, A. G. Eventos Extremos: Estudo da Chuva de Granizo de 21 de Abril de 2008 na Cidade de Maringá-PR. Revista Brasileira de Climatologia, v. 5, 2017.

https://doi.org/10.5380/abclima.v5i0.50483

BOSCO, L. C. et al. Apple production and quality when cultivated under anti-hail cover in southern brazil. International Journal of Biometeorology. 59 (7), 2015.

https://doi.org/10.1007/s00484-014-0893-6

CANEVER, A. P.; LAUREANO JUNIOR, R. O. Ajuda humanitária em Santa Catarina: desastres envolvendo granizo. Revista Ordem Pública, v. 9, n. 1, p. 235-246, 2016.

CAPOZZI, V. et al. Fuzzy-logic detection and probability of hail exploiting short-range X-band weather radar. Atmospheric Research, v. 201, p. 17-33, 2018.

https://doi.org/10.1016/j.atmosres.2017.10.006

CARAMORI, P. H. et al. Agrometeorologia operacional no estado do Paraná. Agrometeoros, v. 24, n. 1, 2016.

https://doi.org/10.31062/agrom.v24i1.24882

CASTRO, A. L. C. de. Manual de desastres: Desastres naturais. Brasília: Ministério da Integração Nacional, 2003.

CIDADE, L. C. F. Urbanização, ambiente, risco e vulnerabilidade: em busca de uma construção interdisciplinar. Cadernos Metrópole, v. 15, n. 29, 2013.

CUNHA, G. R, et al. Granizo e cereais de inverno no Rio Grande do Sul. Passo Fundo: Embrapa Trigo, 2001.

DAFIS, S. et al. Observational and modeling study of a mesoscale convective system during the HyMeX-SOP1. Atmospheric Research, v. 187, p. 1-15, 2017. https://doi.org/10.1016/i.atmosres.2016.12.001

DOLATI, S. H. et al. Hail impact damage behaviors of glass fiber reinforced epoxy filled with nanoclay. Journal of Composite Materials, v. 48, n. 10, p. 1241-1249, 2014. https://doi.org/10.1177/0021998313484950

ELY, D. F. Eventos climáticos e mídia impressa em Londrina (PR): construindo uma abordagem a partir da análise do discurso. 8 Simpósio Brasileiro de Climatologia Geográfica, 24 a 29 de agosto de 2008, Alto Caparaó/MG. Anais... (Online). Universidade Federal de Uberlândia.

FREIRE, N. B. C. et al. Vulnerabilidade socioambiental, inundações e repercussões na Saúde em regiões periféricas: o caso de Alagoas, Brasil. Ciência \& Saúde Coletiva, v. 19, p. 37553762, 2014.

https://doi.org/10.1590/1413-81232014199.07572014

KLANOVICZ, J. Chuvas de granizo e desastre nos pomares de maçã catarinenses: produzindo uma agricultura de risco. Esboços-Revista do Programa de Pós-Graduação em História da UFSC, v. 20, n. 30, p. 67-89, 2013. https://doi.org/10.5007/2175-7976.2013v20n30p67

KREUZ, C. L, et al. Viabilidade econômica do uso da tela antigranizo em pomares de pêra 
japonesa. Revista Brasileira de Fruticultura, agosto de 2002, p. 416- 419. https://doi.org/10.1590/S0100-29452002000200027

KUROSAKI, A. B. et al. Análise de viabilidade econômica de sistema convencional e sistema com uso de telado na produção de ameixa (Prunus domestica), em condições de risco de granizo, na região de Botucatu-SP. Científica, v. 35, n. 1, p. 1-9, 2007.

LAURENT, $\mathrm{H}$. et al. How important is the contribution of the mesoscale convective complexes to the Sahelian rainfall?. Physics and Chemistry of the Earth, v. 23, n. 5-6, p. 629-633, 1998. https://doi.org/10.1016/S0079-1946(98)00099-8

LYONS, W. A. The handy weather answer book. Detroit: Visible Ink, 1997. 397 p.

MARCELINO, E. V. et al. Mapeamento de risco de desastres naturais no estado de Santa Catarina. Caminhos de Geografia. Fevereiro de 2006, p. 72-84.

MARTINS, J. A. et al. Climatology of destructive hailstorms in Brazil. Atmospheric Research, v. 184, p. 126-138, 2017.

https://doi.org/10.1016/j.atmosres.2016.10.012

MENDONÇA, F. A. Riscos, vulnerabilidade e abordagem socioambiental urbana: uma reflexão a partir da RMC e de Curitiba. Desenvolvimento e Meio ambiente, v. 10, 2005.

https://doi.org/10.5380/dma.v10i0.3102

MENDONÇA, F. et al. Resiliência socioambiental-espacial urbana a inundações: possibilidades e limites no bairro Cajuru em Curitiba (PR). Revista da ANPEGE, v. 12, n. 19, p. 279-298, 2016.

https://doi.org/10.5418/RA2016.1219.0012

METZ, A. J. et al. Estudo de impacto de chuva de granizo sobre coberturas residenciais com telhas de fibrocimento e de materiais reciclados. Seminário de Iniciação Científica, p. 168. 2017

MEZHER, R. N. et al. Climatology of hail in Argentina. Atmospheric research, v. 114, p. 70-82, 2012.

https://doi.org/10.1016/i.atmosres.2012.05.020

MIDDLETON, S.; MCWATERS, A. Hail netting of apple orchards australian experience.

Compact Fruit Tree, v. 35, n. 2, p. 51-55, 2002.

MOTA, C. S. et al. Comportamento vegetativo e produtivo de videiras "Cabernet Sauvignon" cultivadas sob cobertura plástica. Revista Brasileira de Fruticultura. Março de 2008, p. 148153.

https://doi.org/10.1590/S0100-29452008000100027

NESET, T. et al. Evaluation of indicators for agricultural vulnerability to climate change: The case of Swedish agriculture. Ecological Indicators, 2018.

https://doi.org/10.1016/j.ecolind.2018.05.042

PUNGE, H. J.; KUNZ, M. Hail observations and hailstorm characteristics in Europe: A review. Atmospheric Research, v. 176, p. 159-184, 2016.

https://doi.org/10.1016/j.atmosres.2016.02.012

PUNGE, $\mathrm{H}$. J. et al. Hail frequency estimation across Europe based on a combination of overshooting top detections and the ERA-INTERIM reanalysis. Atmospheric Research, v. 198, p. 34-43, 2017.

https://doi.org/10.1016/j.atmosres.2017.07.025

SCAGLIONI, T. P.; SARAIVA, J. M. B. Climatologia dos sistemas precipitantes para o período 
Ocorrência, frequência e danos das precipitações de granizo na região metropolitana de Curitiba
Nathan Felipe da Silva Caldana

Paulo Henrique Caramori

Angela Beatriz Ferreira da Costa Glauco Marighella Ferreira da Silva

de fevereiro a dezembro de 2003, no Rio Grande do Sul. In: Congresso Brasileiro De Meteorologia. 2004.

SILVA, G. M. F. et al. O Jornal Como Fonte de Informação Sobre Precipitações de Granizo no Estado Do Paraná. Revista GeoNorte, v. 1, p. 1079-1090, 2012

TREFALT, S. et al. A Severe Hail Storm in Complex Topography in Switzerland-Observations And Processes. Atmospheric Research, v. 209, p. 76-94, 2018. https://doi.org/10.1016/j.atmosres.2018.03.007

VIANA, D. R. et al. Avaliação de desastres no Rio Grande do Sul associados a complexos convectivos de mesoescala. Revista Sociedade \& Natureza, v. 21, n. 2, 2009.

https://doi.org/10.1590/S1982-45132009000200007

WILK, J. et al. The perspectives of the urban poor in climate vulnerability assessments-The case of Kota, India. Urban climate, v. 24, p. 633-642, 2018.

https://doi.org/10.1016/j.uclim.2017.08.004

Recebido em: 15/06/2018

Aceito para publicação em: 04/10/2018 